\title{
ETRANS: An Energy Transport System Optimization Code for Distributed Networks of Solar Collectors
}

J. S. Barnhart

September 1980

Prepared for the U.S. Department of Energy under Contract DE-AC06-76RLO 1830

Pacific Northwest Laboratory Operated for the U.S. Department of Energy by Battelle Memorial Institute 


\title{
NOTICE
}

This report was prepared as an account of work sponsored by the United States Government. Neither the United States nor the Department of Energy, nor any of their employees, nor any of their contractors, subcontractors. or their employees, makes any warranty, express or implied, or assumes any legal liability or responsibility for the accuracy. completeness or usefulness of anv information, apparatus. product or process disclosed, or represents that its use would not infringe privately owned rights.

The views, opinions and conclusions contained in this report are those of the contractor and do not necessarily represent those of the United States Government or the United States Department of Energy.

\author{
PACIFIC NORTHWEST LABORATORY \\ operated by \\ BATTELLE \\ for the \\ UNITED STATES DEPARTMENT OF ENERGY \\ Under Contract DE-AC06-76RLO 1830
}
Printed in the United States of America
Available from
Vational Technical Information Service
United States Department of Commerce
5285 Port Royal Road
Springfield. Virginia 22151

Price: Printed Copy s

$\because$ Microfiche $\$ 3.00$

$\begin{array}{cr}\text { •Pages } & \text { Selling Price } \\ & \\ 001-025 & \$ 4.00 \\ 026-050 & \$ 4.50 \\ 051-075 & \$ 5.25 \\ 076-100 & \$ 6.00 \\ 101-125 & \$ 6.50 \\ 126-150 & \$ 7.25 \\ 151-175 & \$ 8.00 \\ 176-200 & \$ 9.00 \\ 201-225 & 59.25 \\ 226-250 & \$ 9.50 \\ 251-275 & \$ 10.75 \\ 276-300 & \$ 11.00\end{array}$


ETRANS: AN ENERGY TRANSPORT

SYSTEM OPTIMIZATION CODE

FOR DISTRIBUTED NETWORKS

OF SOLAR COLLECTORS

J. S. Barnhart

September 1980

Prepared for

the U.S. Department of Energy

under Contract DE-ACO6-76RLO 1830

Pacific Northwest Laboratory Richland, Washington 99352 
$\checkmark$ 


\section{SUMMARY}

The optimization code ETRANS was developed at the Pacific Northwest Laboratory to design and estimate the costs associated with energy transport systems for distributed fields of solar collectors. The code uses frequently cited layouts for dish and trough collectors and optimizes them on a sectionby-section basis. The optimal section design is that combination of pipe diameter and insulation thickness that yields the minimum annualized systemresultant cost. Among the quantities included in the costing algorithm are 1) labor and materials costs associated with initial plant construction, 2) operating expenses due to daytime and nighttime heat losses, and 3) operating expenses due to pumping power requirements.

Two preliminary series of simulations were conducted to exercise the code. The results indicate that transport system costs for both dish and trough collector fields increase with field size and receiver exit temperature. Furthermore, dish collector transport systems were found to be much more expensive to build and operate than trough transport systems. ETRANS itself is stable and fast-running and shows promise of being a highly effective tool for the analysis of distributed solar thermal systems. 


\section{ACKNOWLEDGMENTS}

This work was supported by the U.S. Department of Energy's Division of Solar Thermal Energy Systems. The author expresses his grateful appreciation to the following individuals for their contributions: W. W. Laity and W. J. Apley for management support; S. P. Bird and M. K. Drost for computer consultation and sound technical advice; F. Ono for manuscript typing; and A. J. Currie for editing. 


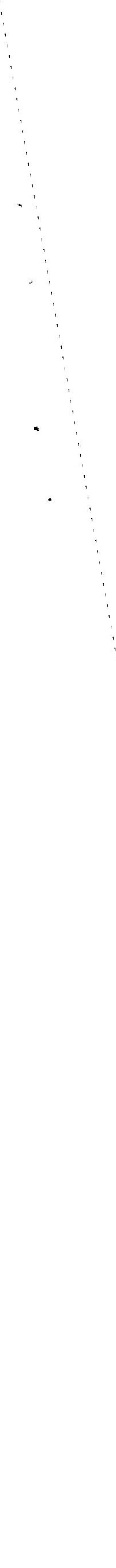


CONTENTS

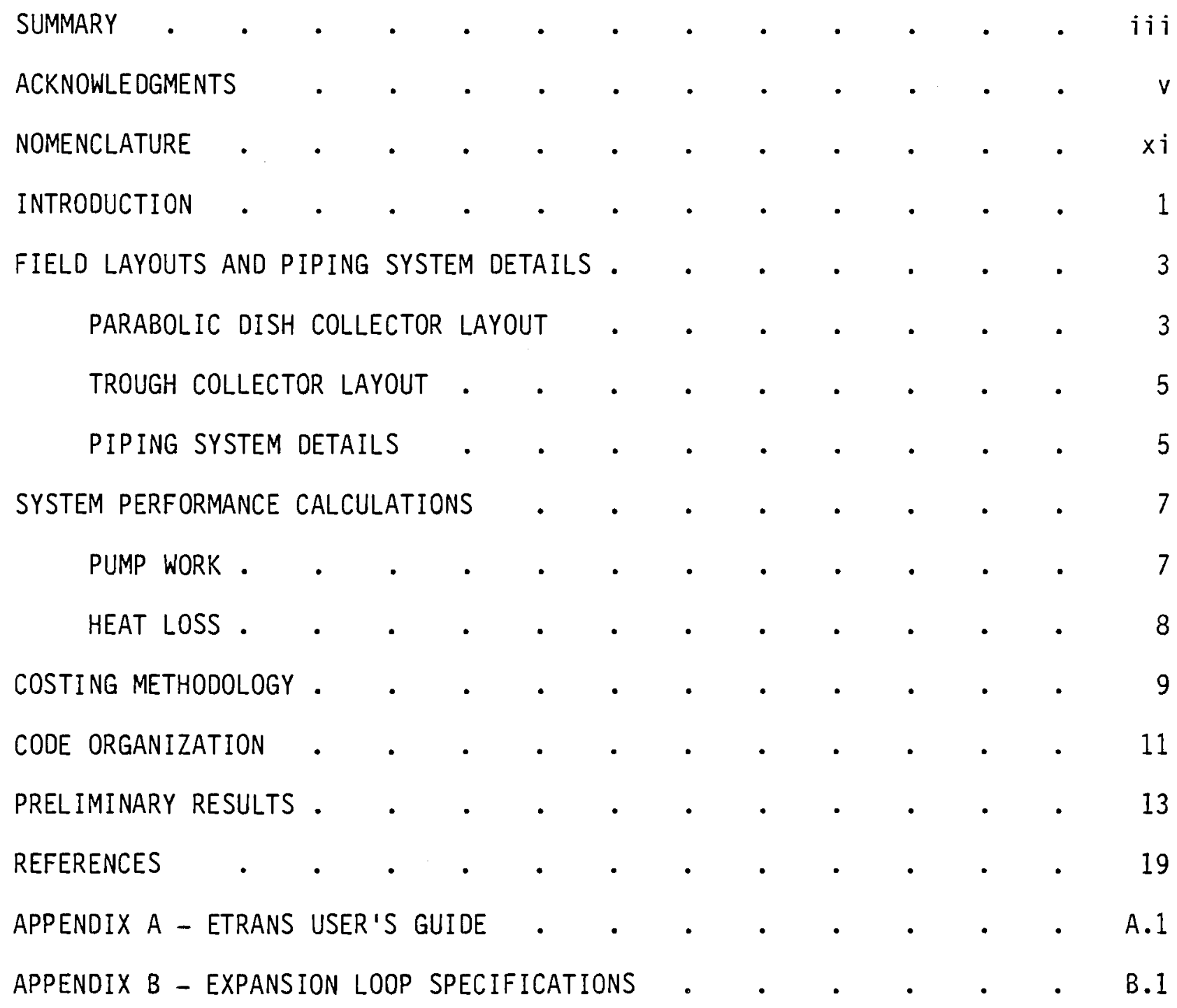





\section{FIGURES}

1 Parabolic Dish Collector Field Layout with Detailed View of Collector Riser and Downcomer Piping . $\quad . \quad$. $\quad . \quad$. 44

2 Trough Collector Field Layout . . . . . . . . 6

3 ETRANS Solution Procedure Outline . • . • • . • 12

4 Dish and Trough Collector Field Transport System Capital Investments at Three Nominal Field Power Ratings . . . . 15

5 Dish and Trough Collector Field Transport System Heat Losses at Three Nominal Field Power Ratings . . . . . 17

6 Dish and Trough Collector Field Transport System Pump Power Requirements at Three Nominal Field Power Ratings . . . . 18

A.1 ETRANS Sample Input Deck • • • • • • • • • • A.2

\section{TABLES}

1 Input for 50-Megawatt Nominal Dish and Trough Field

B.1 Expansion Loop Height Specification for Various Pipe Diameters . 


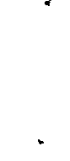

$\checkmark$

- 
NOMENCLATURE

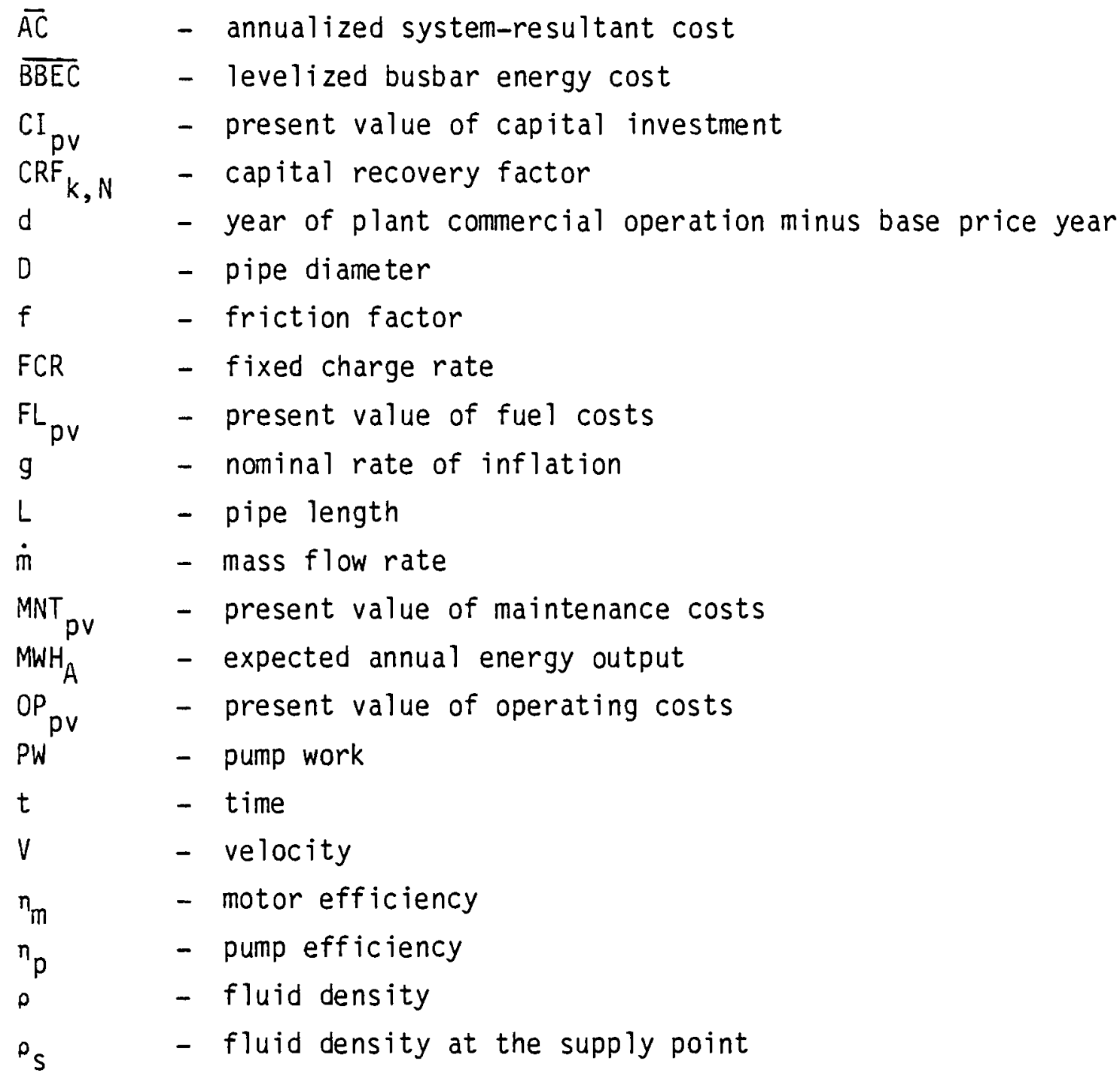




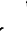

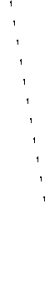


ETRANS: AN ENERGY TRANSPORT SYSTEM OPTIMIZATION CODE

FOR DISTRIBUTED NETWORKS OF SOLAR COLLECTORS

\section{INTRODUCTION}

Distributed fields of solar collectors are often cited as promising tools for harnessing the sun's power for electric and process heat applications. Such fields generally consist of parabolic dish or trough concentrators that focus the sun's rays on receivers through which a working fluid passes. The fluid is then piped back to a central plant where it passes through a heat exchanger or is used directly in the process. The cost of utilizing the sun's energy in this manner is strongly dependent on the design of the energy transport system. The object of the study reported here is to assess energy transport system capital and operating costs for a wide variety of field sizes and operating temperatures.

This task is being carried out at the Pacific Northwest Laboratory (PNL) as part of the Large Power Systems Project sponsored by the U.S. Department of Energy's Division of Solar Thermal Energy Systems. Four power levels (50, 150, 300 , and $600 \mathrm{MWt}$ ) and five operating temperatures (375, 450, 550, 800, and $1100 \mathrm{~K}$ ) are to be investigated. Several collector types are to be included, which, for this task, can be characterized as either parabolic dish or trough collectors. The wide range of operating temperatures requires the use of several working fluids, including water, steam, oil, molten salt, and possibly air.

The ETRANS (Energy TRANsport System) code was developed at PNL to investigate this wide range of cases. The code incorporates those features from several previous investigations (Powell et a1. 1974; Caputo 1975; Williams 1978; I annucci 1980) deemed to be in keeping with the needs of this study. The variety and number of simulations to be conducted made flexibility and economy prime considerations. Two field layouts--one for dish collectors and one for troughs--were incorporated. Previously optimized subfield modules can also be connected along large manifolds to provide additional flexibility. Pipe sections are optimized individually by an iterative process that finds 
the combination of pipe diameter and insulation thickness leading to the lowest life cycle cost. Included in the cost estimates are pipe, insulation, valves and fittings, expansion loops, pipe supports, labor, and projections of operating expenses due to heat loss and pumping power. The primary results obtained from the code include the capital investment required, the total heat loss and pumping power and the resulting operating expenses, and a tabulation of the lengths of piping and insulation of each size required.

This report first describes the field layouts employed and the piping system details. System performance calculations are then discussed; these include pressure drop and day and night heat losses. The costing methodology, based on the work of Doane et al. (1976), is briefly discussed, followed by a description of the code organization. Finally, the results of a preliminary series of simulations are presented and discussed. A user's guide is appended to assist with the preparation of input for ETRANS simulations. 


\section{FIELD LAYOUTS AND PIPING SYSTEM DETAILS}

The location of collectors in a field clearly involves a tradeoff between the desire to minimize shading and the cost penalties of overly long pipe runs. Because the scope of this investigation does not include a full examination of this question, field layouts commonly cited in the literature were used. Because dish and trough collector geometries are so markedly different, ETRANS includes separate field layouts for the two collector types. Another feature allows the user to place previously optimized subfields in a double row along a manifold, providing additional siting flexibility.

The design and specification of a large, multipath piping system is also a difficult task. Considerations such as valving, expansion loops, and pipe supports can obviously have a great impact on costs. Fortunately the very thorough report of Powell et al. (1974) addresses many of these topics and was used extensively in this effort.

PARABOLIC DISH COLLECTOR LAYOUT

The parabolic dish layout shown in Figure 1 is based upon similar geometries employed by Caputo (1975) and Williams (1978). Sections are numbered according to the purely arbitrary scheme shown. Ideally the plant is located in the center of a square symmetrical field of collectors; thus, only the oneeighth section of symmetry shown in Figure 1 need be analyzed. Apley (1979) has shown that shading is minimized when consecutive east-west rows are offset from each other by $50 \%$ rather than the square array shown. Such an arrangement introduces slight distortions to the piping arrangement but need not be modeled with a separate layout. The field supply (cold) and return (hot) lines are collinear and are supported above ground. Note the gate valves located on each main header adjacent to the plant.

Each section in the main headers and in the branches emanating from the headers is individually optimized. In addition to these sections, each collector has associated with it a riser and downcomer (see inset, Figure 1); these are optimized in groups using nominal fluid conditions. Gate valves on either side of the collector can be closed for maintenance. A control valve in the 


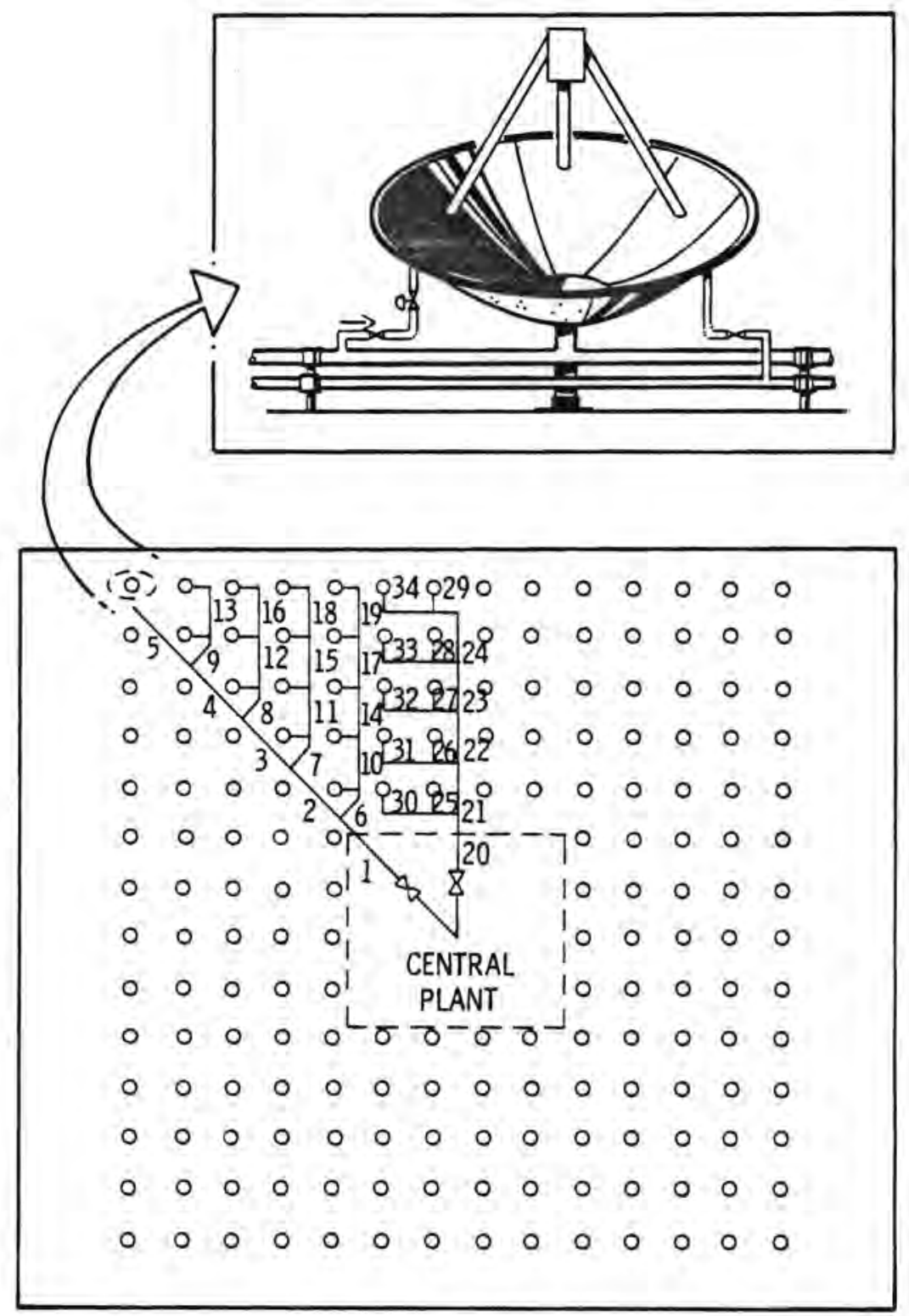

FIGURE 1. Parabolic Dish Collector Field Layout with Detailed View of Collector Riser and Downcomer Piping

riser (or downcomer) regulates the flow to maintain a constant receiver exit temperature. The riser and downcomer follow the receiver support struts to minimize shading. 
TROUGH COLLECTOR LAYOUT

The trough collector layout shown in Figure 2 is based upon a network proposed by Kast, Ortiz, and Whitehouse (1979). In this view the plant is once again located in the center of the field, although it need not be. Although the supply and return lines are once again collinear, both are shown in Figure 2 for clarity. In this "fold-over" arrangement, cold fluid flows through one long string of collectors, then through a short connecting piece, and back to the return header through another string of collectors. The number of collectors placed in series is limited primarily by pressure drop constraints.

Valving on the risers and downcomers is identical to that shown in Figure 1 for the dish collectors. However, these sections are typically much shorter for trough collectors. The U-shaped connecting pieces are optimized as a group, as are the risers and downcomers.

\section{PIPING SYSTEM DETAILS}

Piping and insulation tables are chosen external to the code on the basis of cost, operating pressure, temperature, and compatibility with the working fluid. Pipe wall thickness is determined via the standard formula from Part 2 of the Code for Power Piping (ANSI B31.1.0-1967) as reported in Caputo (1975) and Baumeister, Avalione, and Baumeister (1978). The user may specify completely different pipe and insulation tables for the supply and return sides of the field to take advantage of the lower temperature on the supply side. The $r$ ange of pipe sizes read in is based upon the design flow rates throughout the field; tables currently in use employ 1.27- to 61-cm (1/2- to 24-in.) nominal pipe diameters. Powell et al. (1974) report that, for large-diameter ( $\geq 51 \mathrm{~cm}$ ) pipes, it is often cheaper to install two or more smaller pipes of roughly the same capacity; this option has also been provided in ETRANS.

The locations of fittings and supports within the field are largely dictated by necessity. Fittings are welded into the lines. (Valves and receivers, however, are flanged.) Support spacing and design are based on tabulated data in Powell et al. (1974) and Baumeister, Avalione, and Baumeister (1978). Expansion loops are U-shaped and are spaced according to a convenient field 


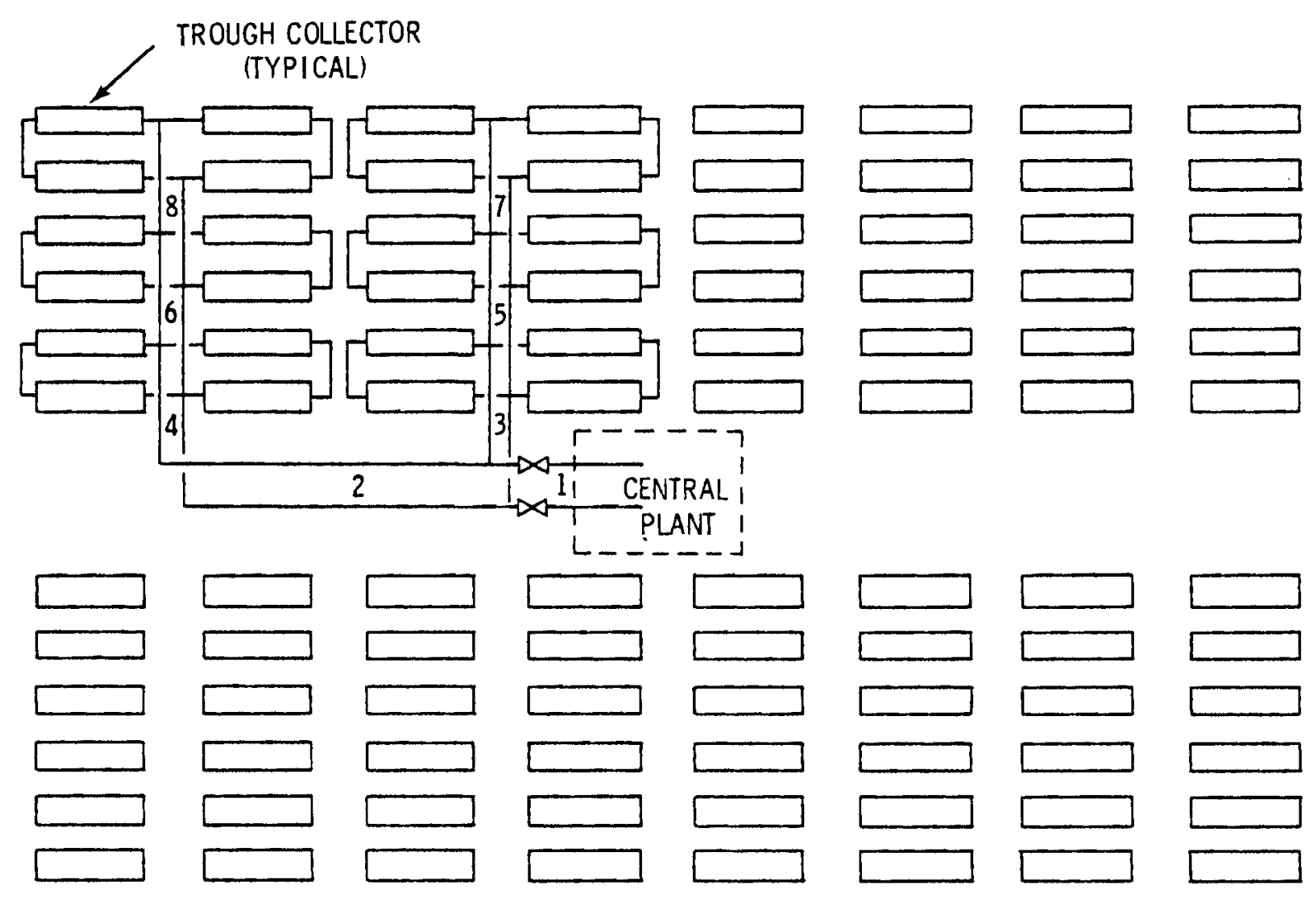

FIGURE 2. Trough Collector Field Layout

dimension. The length of each expansion loop is based on tabular values in Powell et al. and adjusted for operating temperature, interloop spacing, and material properties.

In some systems the working fluid itself will be of significant cost. ETRANS includes both the initial cost of filling the field and the expense of continuous replenishment. Molten salt and some oil fields will probably require heat tracing to prevent freezing; here again, both the capital and operating expenses are included.

The capital cost for peripheral items such as pumps, motors, and storage tanks may also be read into ETRANS to provide a complete accounting of initial costs. 


\section{SYSTEM PERFORMANCE CALCULATIONS}

The performance of the energy transport system is characterized by the pump power required and the heat losses incurred. The pump power and daytime heat loss are calculated on a section-by-section basis via a steady-state analysis using average values for fluid flow, ambient temperature, and collector performance. The nighttime heat loss model also uses an average ambient temperature and assumes that the working fluid lies stagnant in the pipe network. Local fluid properties (section inlet values) are used in all cases except for collector risers, downcomers, and connecting pieces for which nominal fluid properties are used.

\section{PUMP WORK}

The energy required to pump the working fluid through a section for a period of $t$ hours per day is calculated as

$$
P W=\left[f\left(\frac{L}{D}\right)_{e q} \rho \frac{V^{2}}{2}\right]\left[\begin{array}{lll}
\dot{m} & t \\
\hline \rho_{s} & n_{p} & n_{m}
\end{array}\right]
$$

Important assumptions utilized in Equation (1) include

- fully turbulent flow through smooth pipes

- resistance to flow of valves and fittings expressed in terms of $(L / D)_{\mathrm{eq}}$ with values based on Crane (1974)

- the aforementioned assumption of steady flow at average conditions.

This equation is used with each candidate pipe size for a given section to determine the corresponding pumping costs.

Implicit in this section-by-section optimization routine is the assumption that the optimal diameter for a section may be specified without regard to its location in the field. However, because each field consists of several parallel flow paths, all of which are constrained to undergo the same net pressure drop, this assumption is incorrect. Those sections located in 
shorter loops can often be made smaller than the apparent optimum with no resulting increase in pump work due to the need to throttle most of the flows. During the first pass through the field, however, the amount of "extra" pressure drop available in each loop is unknown, and each section is sized according to the method described above. To take advantage of the need to equalize loop pressure drops, ETRANS makes a second (optional) pass through the field, downsizing sections where possible to reduce capital costs. A bonus is the simultaneous reduction in heat loss due to the smaller pipe sizes.

HEAT LOSS

For both day and night heat loss calculations, the pipe is assumed to be at fluid temperature and the outside of the insulation at ambient temperature. This implies that the insulation is the only significant barrier to heat flow. The daytime heat loss calculation thus reduces to the straightforward analysis of a fluid flowing at steady state through a single-walled cylinder.

For night heat loss calculations, the fluid is assumed to be stagnant and may initially be subcooled, two-phase, or superheated. Depending upon the fluid's initial state and the rate of heat loss, the fluid may remain in its initial state or drop to a lower one (e.g., from superheated to subcooled). The analysis is complicated by other factors as we11: 1) the temperature of a two-phase mixture remains constant as it loses heat, while that of subcooled and superheated fluids does not; 2) the thermal capacitance of the pipe (assumed to be at fluid temperature) must be accounted for; and 3) the thermal conductivity of the insulation may change greatly with temperature. ETRANS covers these contingencies by way of a rather complicated analysis that includes considerable logic to cover all possible situations.

For heat-traced systems the analysis is more complicated still. When the calculations show that the fluid will freeze before the night ends, heat trace power is turned on at the level required to maintain the fluid at the freezing point. The cost of the heat trace energy is then added to the other operating expenses and thus becomes another element in the life cycle cost. In this way ETRANS determines directly whether it is more cost-effective to run the heat tracing or to install thicker insulation. 
COSTING METHODOLOGY

As noted previously, the optimal section design is that combination of pipe diameter and insulation thickness that results in the lowest total cost over the lifetime of the plant. Comparing on this basis amounts to striking the proper balance between capital investments and operating and maintenance expenses. A convenient and sound measure of lifetime cost is the annualized system-resultant cost, fully described in Doane et a1. (1976) and repeated here as Equation (2):

$$
\overline{A C}=(1+g)^{-d}\left[F C R \cdot C I_{p v}+C R F_{k, N}\left(O P_{p v}+M N T_{p v}+F L_{p v}\right)\right]
$$

The annualized system-resultant cost $(\overline{A C})$ has units of dollars per year and represents an amount which, if collected in revenues each year, would constitute a revenue distribution with exactly the same present value as the summed present values of the separate cost distributions. Equation (2) shows $\overline{A C}$ to be a weighted sum of the present value of capital investment $\left(\mathrm{CI}_{p v}\right)$ and the present values of recurrent costs for operations, maintenance, and fuel. (Fue 1 charges in this case are, of course, zero.) The weighting factor for capital investments is the fixed charge rate (FCR), which incorporates utilitydependent data such as taxation rate and insurance premiums. The weighting factor for recurrent costs is the capital recovery factor (CRF), which represents the uniform annual payment, as a fraction of the original principal, necessary to pay back a loan over a specified period.

Further insight into the annualized system-resultant cost is provided by noting its relationship to the levelized busbar energy cost (Doane et al. 1976):

$$
\overline{B B E C}=\overline{A C} / M_{A}
$$

where $\mathrm{MWH}_{A}$ is the expected annual energy output for the system. Thus, comparing piping sections on the basis of $\overline{A C}$ is equivalent to comparing power plants on the basis of busbar cost, a practice long in use. Employing $\overrightarrow{A C}$ rather than the busbar cost obviates the need to simulate the performance of 
the power system. Doane et al. (1976) provide a more thorough discussion of this and other concepts presented in this section. 
CODE ORGANIZATION

The major steps involved in the ETRANS solution procedure are illustrated in Figure 3. As noted previously, the field is optimized on a section-bysection basis using local fluid properties and flow rate. The executive routine MAIN is responsible for stepping through the field, whose size and shape are specified via input. Each section is optimized via the four-step procedure shown in Figure 3. First, MAIN supplies the upstream pressure and enthalpy (known from previous optimizations for most sections, or by input for the first section) to a support subroutine, PROP. The other fluid properties of interest are simply interpolated from tables supplied from input and returned to MAIN.

Second, MAIN passes this information, along with the section length, flow rate, symmetry factor, and the number and type of fittings to be included, to the program workhorse, OPTIM. Component costs and material properties are passed to OPTIM via input. OPTIM consists primarily of two nested DO loops. In the outer loop, the pipe diameter is varied and the pumping costs calculated for each size. In the inner loop, the insulation thickness is varied and the cost due to heat loss calculated for each thickness. Capital costs are summed, total operating expenses are determined, and the annualized system-resultant cost is found for each and every possible combination. The performance and costs of the optimal combination are saved and sent to subroutine ONWARD. This bookkeeping routine uses the section symmetry factor to add the results to the cumulative field totals for later output. Control is then returned to MAIN, where the cycle begins anew.

When both the supply and return sides have thus been completely traversed, subroutine SUMRY is called to print the results. The user may then elect to go through the pipe downsizing routine, referred to in the discussion on pump work, by calling subroutine THROTL. This subroutine performs much like MAIN in that it directs the same four-step sequence to optimize individual sections. The important difference is that pumping costs are irrelevant so long as the pressure drop stays below a specific limit. THROTL determines, for each section within a loop, all the pipe sizes that yield a pressure drop within the 
INPUT: COLLECTOR TYPE, FIELD GEOMETRY, OPERATING

CONDITIONS, FINANCIAL DATA

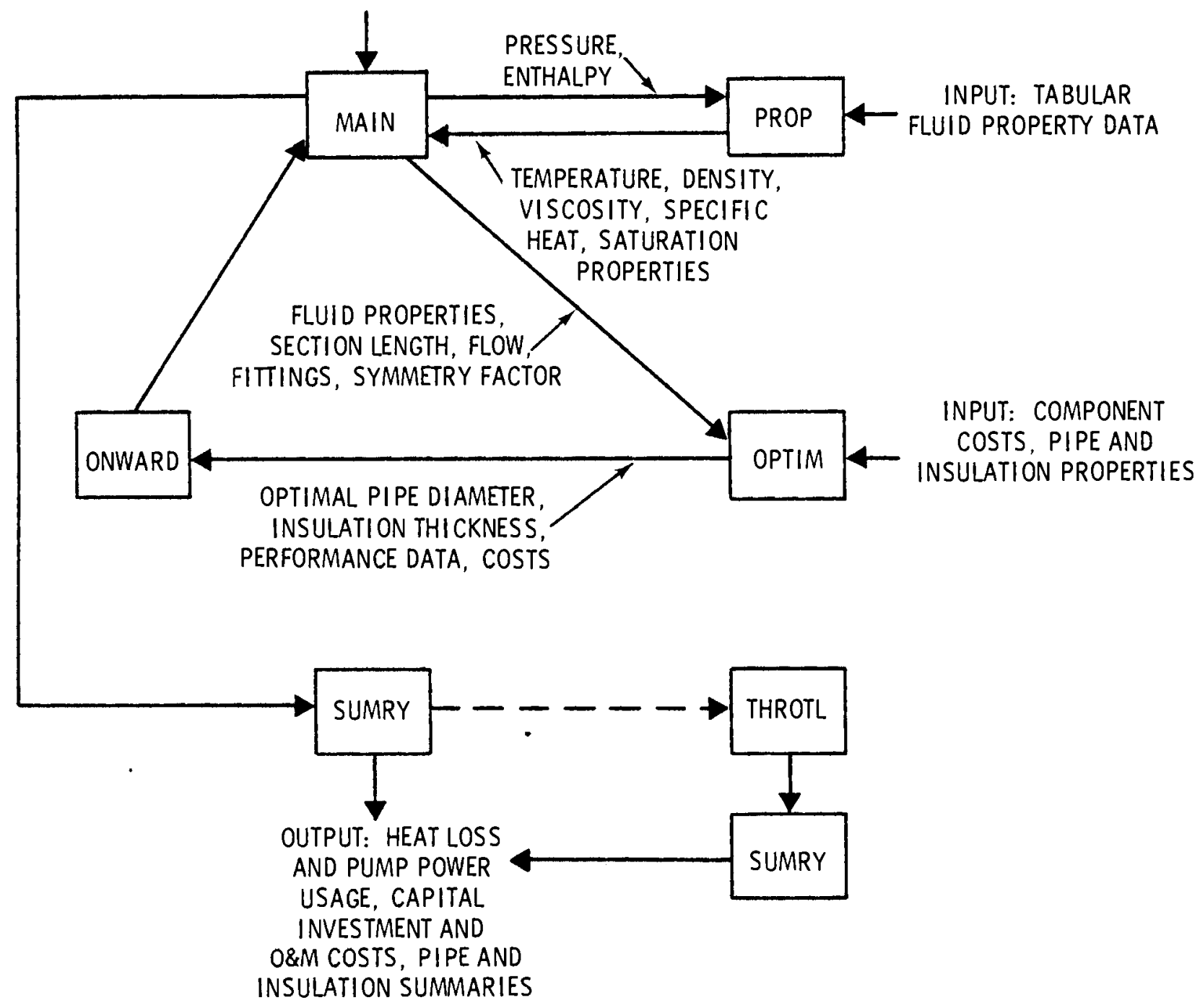

FIGURE 3. ETRANS Solution Procedure Outline

limit. Then, for the loop as a whole, it finds the combination of size reductions that leads to the greatest savings. The appropriate reductions are then made and the corresponding changes in the field totals are logged by subroutine ONWARD. When the process is completed, SUMRY is called once again to print the revised results. 
PRELIMINARY RESULTS

Two brief series of simulations were carried out to test ETRANS with dish and trough collector fields. It must be emphasized at the outset that these analyses are based on highly conjectural cost data and operating conditions and thus are not necessarily indicative of state-of-the-art performance. Nevertheless, the results provide an excellent qualitativ. insight into the performance of transport systems.

Simulations were carried out at nominal power ratings of 50, 400, and 600 MW and fluid return temperatures of 365,450 , and $560 \mathrm{~K}$. The working fluid was pressurized water flowing through carbon steel pipe. A supply pressure of $3450 \mathrm{kPa}$ was used for the $365-$ and $450-\mathrm{K}$ cases, allowing the use of Schedule 40 pipe. The supply pressure for the $560-\mathrm{K}$ runs was $9660 \mathrm{kPa}$, necessitating a switch to Schedule 80 pipe. The 50-MW dish and trough fields were laid out according to the plans shown in Figures 1 and 2, respectively. The 400- and 600-MW fields were created by placing 50-MW subfields in double rows along two symmetrical manifolds radiating out from a central plant. The economic parameters, operating conditions, and field specifications for the 50-MW simulations are summarized in Table 1 . Most of these data carry over directly to the 400- and 600-MW cases, supplemented only by the manifold dimensions.

Plotted in Figure 4 is the capital investment for both dish and trough field energy transport systems expressed in dollars per square meter of collector aperture. Capital investment increases with receiver exit temperature because the potential for greater heat loss makes it advantageous to install thicker insulation. Furthermore, the need to use Schedule 80 pipe for the 560-K runs naturally increases costs. Capital investment also increases with power rating, showing a sharp increase between 50 and $400 \mathrm{MW}$ and a more gradual increase between 400 and $600 \mathrm{MW}$. Caputo (1975) and Iannucci (1980) also report an increase in capital costs with field size, citing the need to use progressively larger pipes to make incremental additions to capacity. (An excellent discussion of this phenomenon appears in Powell et al. (1974).) Based on the results in Caputo and Iannucci, however, it appears that the "diseconomy of scale" between 50 and $400 \mathrm{MW}$ is exaggerated, quite possibly due 
TABLE 1. Input for 50-Megawatt Nominal Dish and Trough Field Simulations

\begin{tabular}{|c|c|}
\hline $\begin{array}{c}\text { Description and Units } \\
\text { Economic Variables }\end{array}$ & Quantity \\
\hline $\begin{array}{l}\text { Plant life, years } \\
\text { Plant construction time, years } \\
\text { Capital recovery factor } \\
\text { Fixed charge rate } \\
\text { General inflation rate } \\
\text { Cost of electricity, } \$ / \mathrm{kWh} \\
\text { Cost of heat loss, } \$ / \mathrm{kWh}\end{array}$ & $\begin{array}{l}30 \\
4 \\
0.094 \\
0.157 \\
0.06 \\
0.09 \\
0.03\end{array}$ \\
\hline
\end{tabular}

Operating Conditions and Field Specifications General

Supply pressure, $\mathrm{kPa}$

Receiver temperature rise, $k$

3450

Hours per day of operation

Pump efficiency

Motor efficiency

Average daytime temperature, $K$

Average nighttime temperature, $K$

Expansion loop spacing, $m$

Parabolic Dish Field

Number of collectors

Average collector power output, $\mathrm{kW}$

Flow per collector, grams/sec

Collector pressure drop, $\mathrm{kPa}$

Dish diameter, $m$

Ground cover ratio

Length of riser and downcomer, $m$

Trough Field

Number of collectors

1024

Average collector power output, $\mathrm{kW}$

Flow per collector, grams/sec

263

Collector pressure drop, $\mathrm{kPa}$

60

Collector length, m

61

Collector width, m

2.75

Ground cover ratio

0.5

Length of riser and downcomer, $m$

2

Length of connecting piece, $m$ 

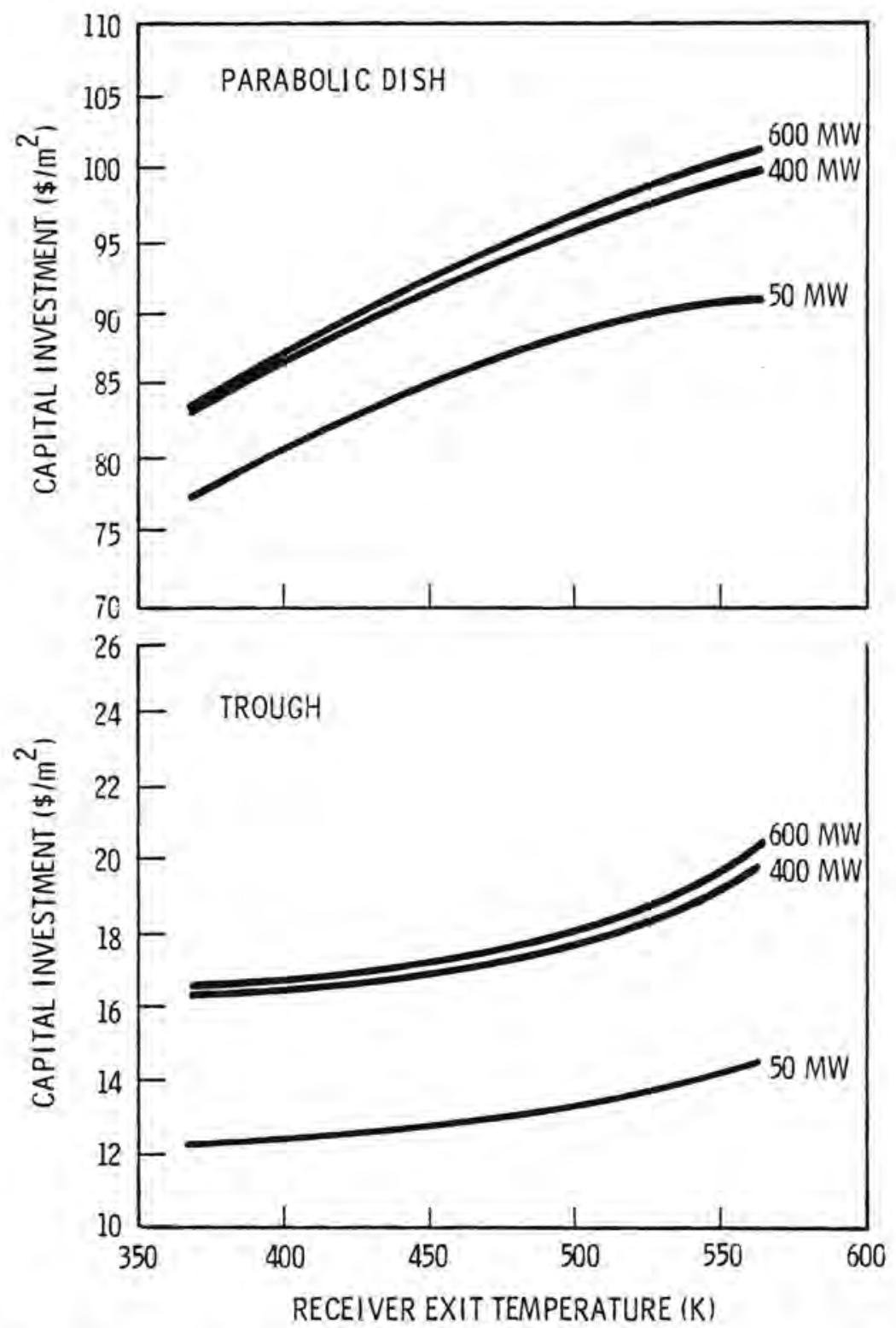

FIGURE 4. Dish and Trough Collector Field Transport System Capital Investments at Three Nominal Field Power Ratings

to the manifold-subfield layout employed. This effect will be examined in subsequent simulations and points out the potential importance of field layout to capital costs.

Perhaps the most striking feature of Figure 4 is the roughly fivefold increase in cost for dish collector transport systems as compared to trough 
systems. Iannucci (1980) reports an even higher ratio of about seven for similar fields. The primary cause is the length of piping required: the 50-MW dish system requires roughly $83 \mathrm{~km}$ of pipe, while the trough system requires only about $13 \mathrm{~km}$. More than half the pipe required in the dish fields is for risers and downcomers.

The trends in heat loss for the dish and trough energy transport systems, illustrated in Figure 5, are similar to those observed in capital investment. Heat loss increases sharply with receiver exit temperature and shows the same trend with field size as exhibited by capital investment. For most of the field piping for the $560-K$ fields, the optimal insulation was the thickest available $(10.2 \mathrm{~cm})$. This indicates that the true optimum may have been somewhat thicker, in which case the heat loss would have been reduced at the expense of still higher capital investments.

The parabolic dish network heat loss is at least twice as great as the trough network heat loss under all conditions. In view of the vastly greater amount of pipe in the dish networks, one wonders why the ratio is not higher. The answer lies largely in the fact that the dish network is made up mainly of small pipes (1.25-cm or 1/2-in. nominal diameter) that have little thermal capacitance and thus lose relatively little heat overnight. For a given insulation thickness, a smaller pipe diameter results in lower daytime heat losses as we 11 .

Also of interest are the pump power requirements for the dish and trough fields; these are plotted in Figure 6. Pump power increases with exit temperature for three reasons: 1) smaller pipe diameters are favored at high temperatures due to reduced heat loss; 2) higher temperatures yield lower fluid densities and thus increased velocities; and 3) the switch to Schedule 80 pipe at $560 \mathrm{~K}$ moves the optimal pipe diameter down due to higher capital costs. The increased pump power requirements with field size are simply due to the greater distances over which fluid must be pumped. Note that, in contrast to the capital investment and heat loss results, the pump power requirements for the dish and trough fields are virtually identical. Pump power is proportional to the product of flow rate and overall field pressure drop because the flows through 

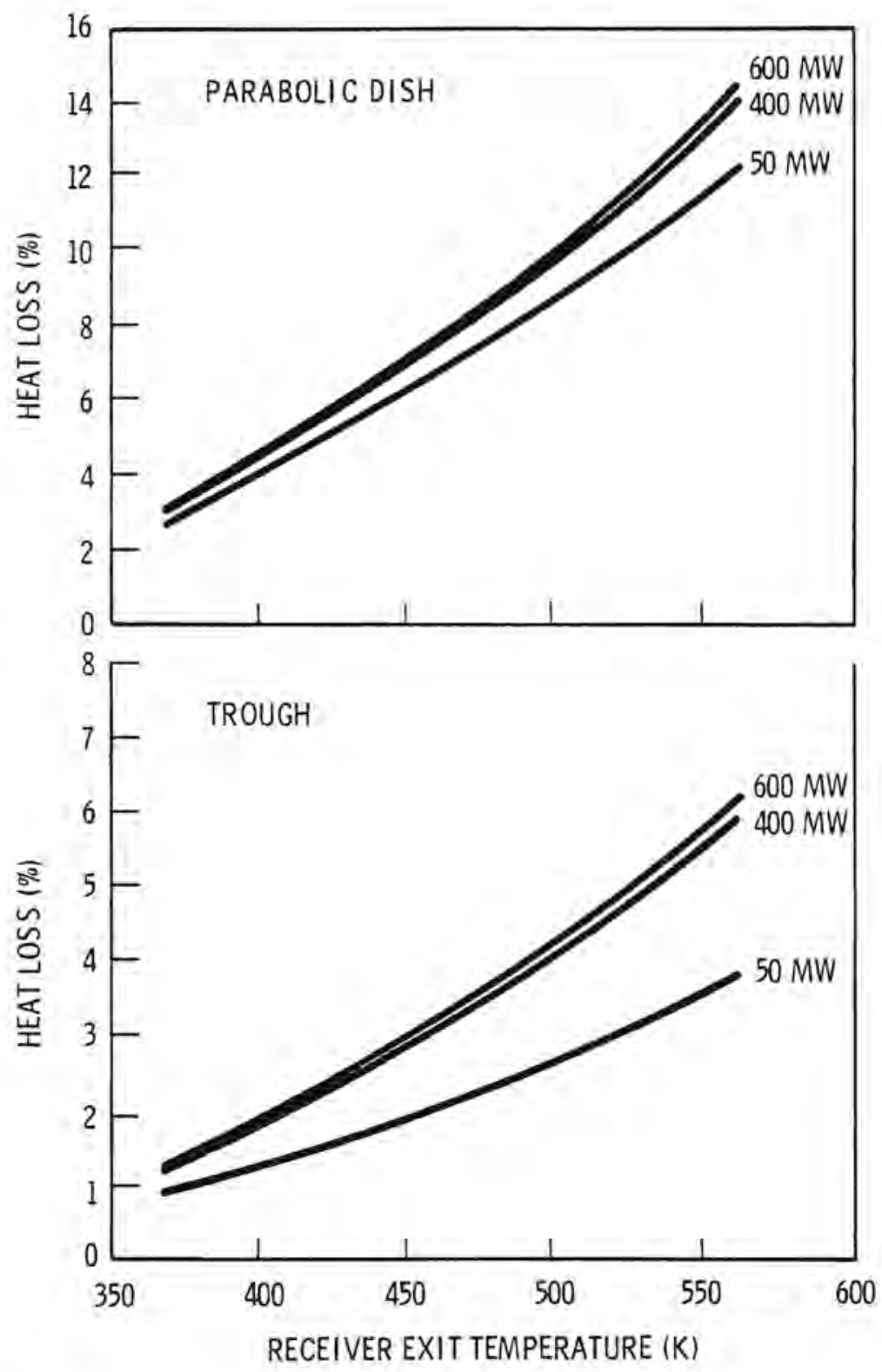

FIGURE 5. Dish and Trough Collector Field Transport System Heat Losses at Three Nominal Field Power Ratings

all parallel paths must undergo the same pressure drop. The total flow rates for the dish and trough fields are very nearly equal; thus, the overall pressure drops must also be virtually equal in spite of their markedly different geometries. Whether or not this equality of pump power is simply coincidental will be examined more thoroughly in future simulations. 

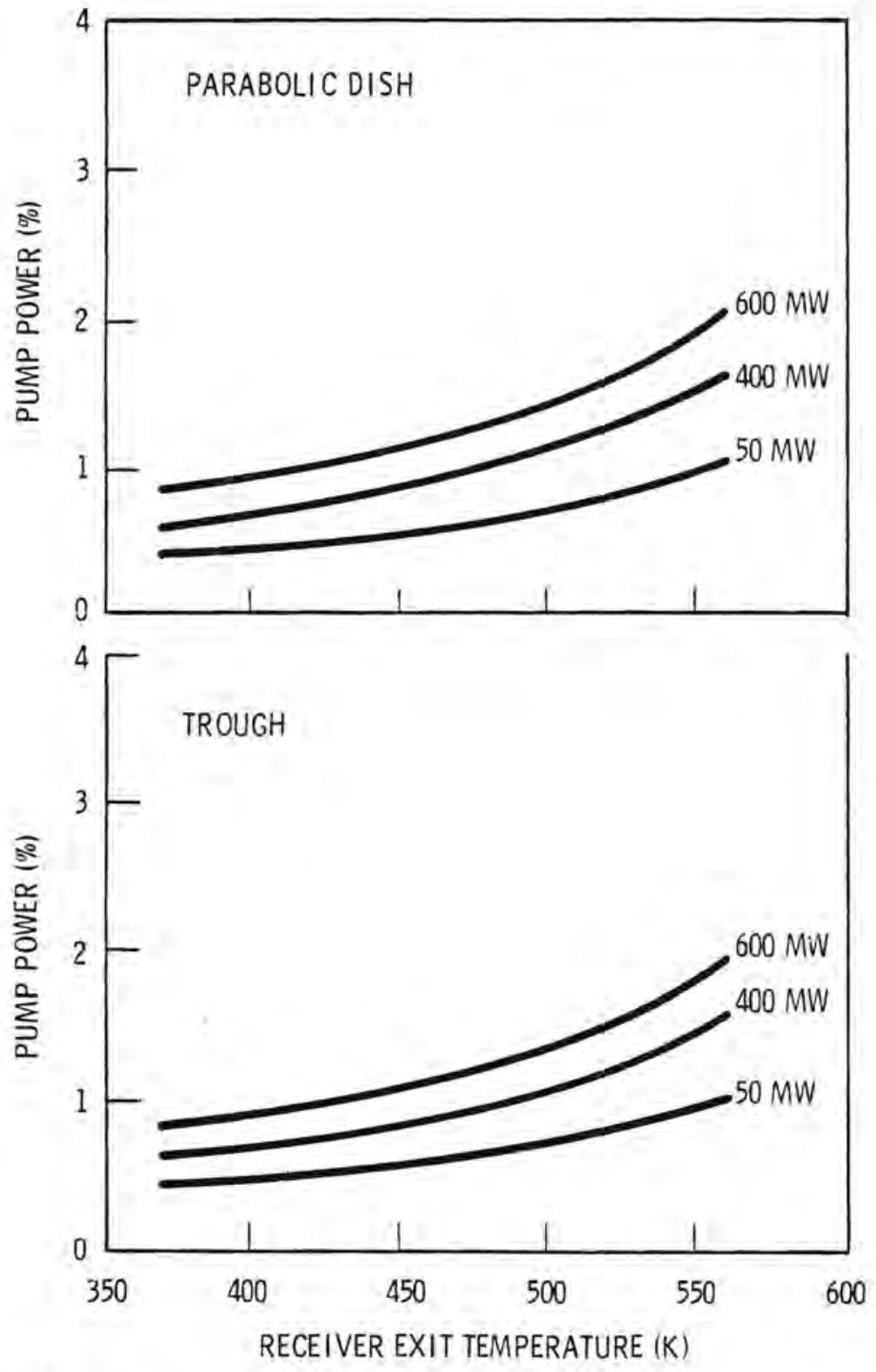

FIGURE 6. Dish and Trough Collector Field Transport System Pump Power Requirements at Three Nominal Field Power Ratings 


\section{REFERENCES}

Apley, W. J. 1979. "SHADE - A Computer Model for Evaluating the Optical Performance of Two-Axis Tracking Parabolic Concentrators." Paper presented at the American Society of Mechanical Engineers 1979 Winter Annual Meeting, New York, New York.

Baumeister, T., E. A. Avallone, and T. Baumeister III. 1978. Marks' Standard Handbook for Mechanical Engineers. 8th ed., Chapter 8, pp. 149-155. McGraw-Hi11, New York, New York.

Caputo, R. 1975. An Initial Study of Solar Power Plants Using a Distributed Network of Point Focusing Collectors. JPL 900-724, Jet Propulsion Laboratory, Pasadena, California.

Crane. 1974. Flow of Fluids Through Valves, Fittings, and Pipe. Crane Co., New York, New York.

Doane, J. W., et al. 1976. The Cost of Energy from Utility-Owned Solar Electric Systems. ERDA/JPL-1012-7613, Jet Propulsion Laboratory, Pasadena, California.

Iannucci, J. J. 1980. "Thermal Energy Centralization Networks: Design, Cost, and Performance for Dish, Trough, and Central Receiver Systems." Paper presented at the International Solar Energy Society Meeting, June 1980, Phoenix, Arizona.

Kast, M., P. Ortiz, and H. Whitehouse. "Solar Production of Industrial Process Steam for Stauffer Chemical Company." In Proceedings of Solar Industrial Process Heat Conference, pp. 327-334. SERI/TP-333-429, Solar Energy Research Institute, GoTden, Colorado.

Powe 11, J. C., et a1. 1974. Dynamic Conversion of Solar Generated Heat to Electricity. NASA CR-134724, Honeywe11, Inc., Minneapolis, Minnesota, and BTack \& Veatch, Kansas City, Missouri.

Williams, 0. M. 1978. "Thermochemical Energy Transport Costs for a Distributed Solar Power Plant." Solar Energy. 20:333-342. 

APPENDIX A

ETRANS USER'S GUIDE 
APPENDIX A

ETRANS USER'S GUIDE

ETRANS is written in Fortran $V$ as used on the Univac 1100/44 computer. Core storage requirement: depend upon the number of sections to be analyzed. ETRANS is currently dimensioned for a 500-section simulation (which, through symmetry, corresponds roughly to 2000- and 4000-collector trough and dish fields, respectively) and requires $20000_{10}$ words of storage. Run time also depends upon field size but is typically less than 2 minutes.

Input for ETRANS simulations is read from punched cards by a subroutine called SETIN. The input is divided into six functional groups:

1. program control variables

2. collector field specifications

3. operating conditions

4. fluid properties

5. financial information

6. piping and insulation data.

Each group will be discussed in turn, including a description of the variables and the formats under which they are read. A sample input deck is provided in Figure A.1 to further clarify the process. The groups are separated by blank cards in the figure; in the actual simulation, however, they follow directly behind one another.

GROUP 1: PROGRAM CONTROL

READ ICASE, IPRINT, NAR, NLIMIT, NDTAIL, ITHRTL, ITYPE

FORMAT 715

ICASE $\equiv a$ unique and arbitrary case number

IPRINT $\equiv$ print option flag, $0 \leq I P R I N T \leq 3$. IPRINT $=0$, print out the input data and stop (useful for checking for encoding errors before running 


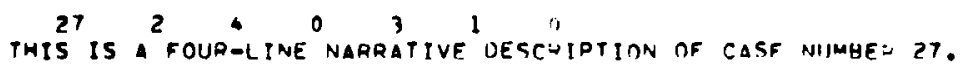

THE USER MAY WRITE ANYTHING HE WISHFS IN THE NARRATIVE, OR HE MAY CHOOSE TO

WAITE NOTHING aT ALL. THE NARHATIVE IS PHINTED WITH THF INPIJT SUMMARY EXACTLY AS IT APPEARS ON THE PUNCHED CAMRG.

(2)

$\begin{array}{lllllllllll}1008 & 138 & 33 & 6 & 17 & 18.7 & 13.4 & 23 . & 33 . & 7 n .50 .30 .\end{array}$

(3)

$$
265.3450 .49 .0 .30 .11 . .4 .4 .95 .95 n .
$$

$534.26 \quad n$.

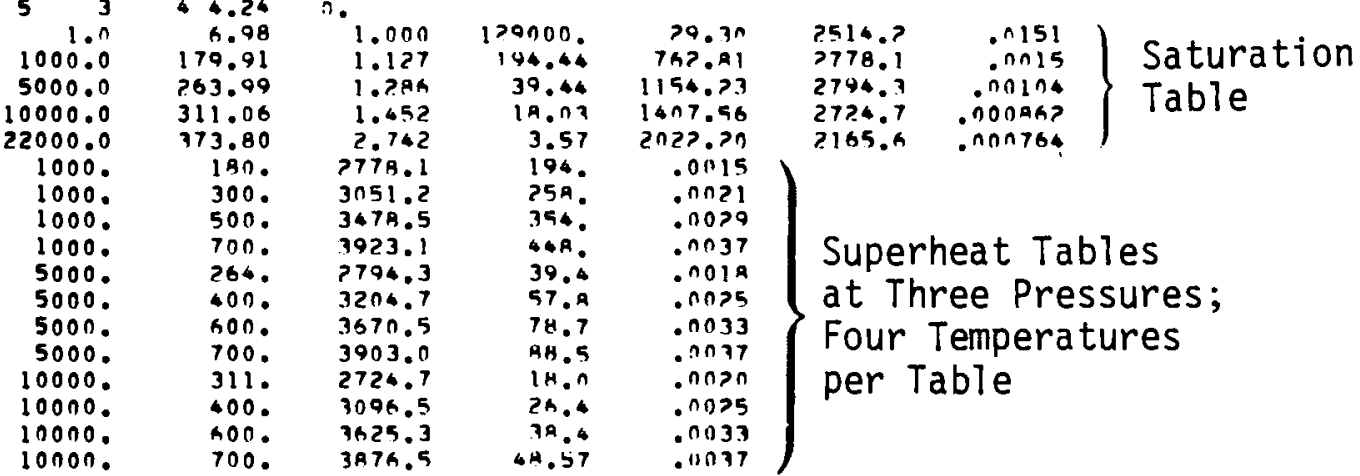

(5) 1.06

$.04 \quad .07$

30

30. 4.1 19a

.157

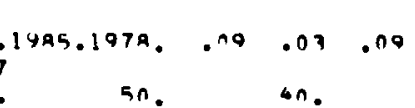

21.000015

$4.09 \quad .000015$
.90

19.4 i2.

$15.4 n$

125.

5.2

30.48

434.

(6)

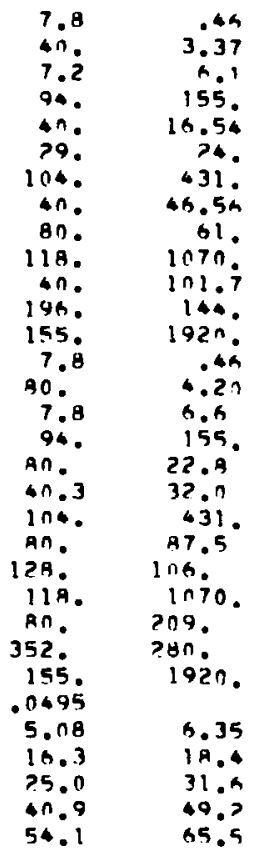

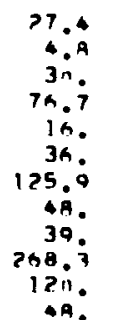

27.4

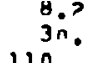

110

$3 n$.

303 .

119.

593.

292.

7.62

$2 ? .6$

36.9

24.1

77.0

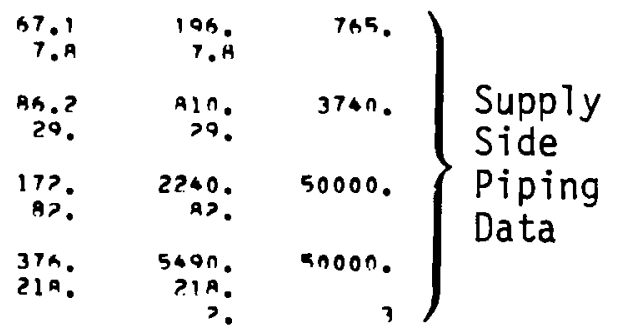

$67.1 \quad 247.0$
8.9

173. 1990.

413. iasn.

$130 . \quad 13 n$.

43.3. LaAnn.

370. 37n:?

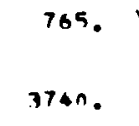

Return

anoon.

snoon.

Piping

Data

9.99

$>9.7$

$4 . .5$

$7 n . ?$
90.3

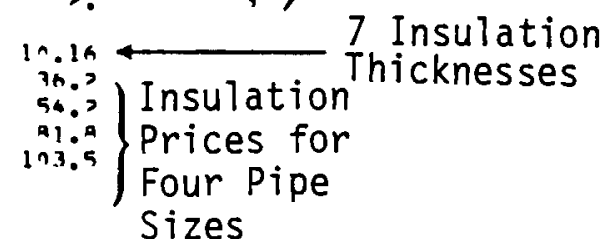

FIGURE A.1. ETRANS Sample Input Deck 
a simulation). IPRINT $=1$, print out the input data, the case summary, and a summary of the pipe downsizing treatment (if specified). IPRINT $=2$, print a performance and cost summary for each pipe section in addition to the above data. IPRINT $=3$, print a performance and cost summary for every combination of pipe diameter and insulation thickness for every section, in addition to the above. (This option should be used with discretion because it produces potentially vast quantities of output.)

NAR Enarrative flag, $0 \leq N A R \leq 5$. The user has the option of reading in a narrative description of the run NAR lines long.

NLIMIT E run limit flag. By making NLIMIT nonzero, the user directs that only sections whose numbers are less than or equal to NLIMIT are to be optimized. The section numbering schemes are shown for dish and trough collector fields in Figures 1 and 2. Collector risers, connecting pieces (for trough fields), and downcomers are numbered -3 , -2 , and -1 , respectively. This parameter is useful for debugging, but must be set to zero to complete a simulation.

NDTAIL $\equiv \operatorname{detailed~output~flag,~} 0 \leq$ NDTAIL $\leq 10$. The user may select up to ten sections for which he wants a print option specification of three (see IPRINT above). NDTAIL is the number of sections, not the section numbers; these are read in on a later card to be discussed shortly.

ITHRTL $\equiv$ pipe downsizing option flag. ITHRTL $=0$, skip the downsizing treatment. $I T H R T L=1$, perform the downsizing treatment.

ITYPE $\equiv$ simulation type flag. ITYPE $=0$, parabolic dish field. ITYPE $=1$, trough field. ITYPE $=2$, modularized field in which previously optimized subfields are arranged in a double row along large headers.

$\rightarrow \quad$ OPTIONAL: NAR >0

READ ((NARTVE (I, J), I = 1, 20), J = 1, NAR)

FORMAT 5(20A4)

NARTVE $\equiv$ an array that contains the narrative description provided by the user. 
$\rightarrow \quad$ OPTIONAL: NDTAIL > 0

READ (NDTL $(I), I=1,10)$

FORMAT 1015

NDTL $\equiv$ an array that contains the numbers of the sections for which detailed output (print option 3 ) is desired.

In the example of Figure A.1, the case number is 27 , the print option is 2 , and the user has supplied a four-line narrative. The user wants a complete simulation so he set NLIMIT $=0$. Detailed output for three sections (the riser, downcomer and section 20) is to be printed. The pipe downsizing routine is specified, and the field to be analyzed is composed of parabolic dishes.

GROUP 2: FIELD SPECIFICATIONS

$\rightarrow \quad$ OPTIONAL: $\quad$ ITYPE $=0$ (dish field)

READ NCFLD, NCOLL, IFIELD, INEAR, IFAR, EWSP, SNSP, CSPIPE, CRPIPE, RCVRDP, RCVRHT, EXPAN

FORMAT 5 I5, 7F5.0

NCFLD $\equiv$ the number of collectors in the entire field

NCOLL $\equiv$ the number of collectors in the section of symmetry to be modeled

IFIELD $\equiv$ the width (or length) of the field (i.e., the field is IFIELD collectors wide)

INEAR $\equiv$ the number of collectors in the row of the section of symmetry nearest the central plant. In the field of Figure 1 , INEAR $=3$.

IFAR $\equiv$ the number of collectors in the row of the section of symmetry farthest from the plant. In Figure 1, IFAR $=7$. For fields in which

IFIELD is odd, the middle row is included in the section of symmetry. collectors along the diagonal of the square field layout are always included.

EWSP $\equiv$ the east-west collector spacing, $m$ 


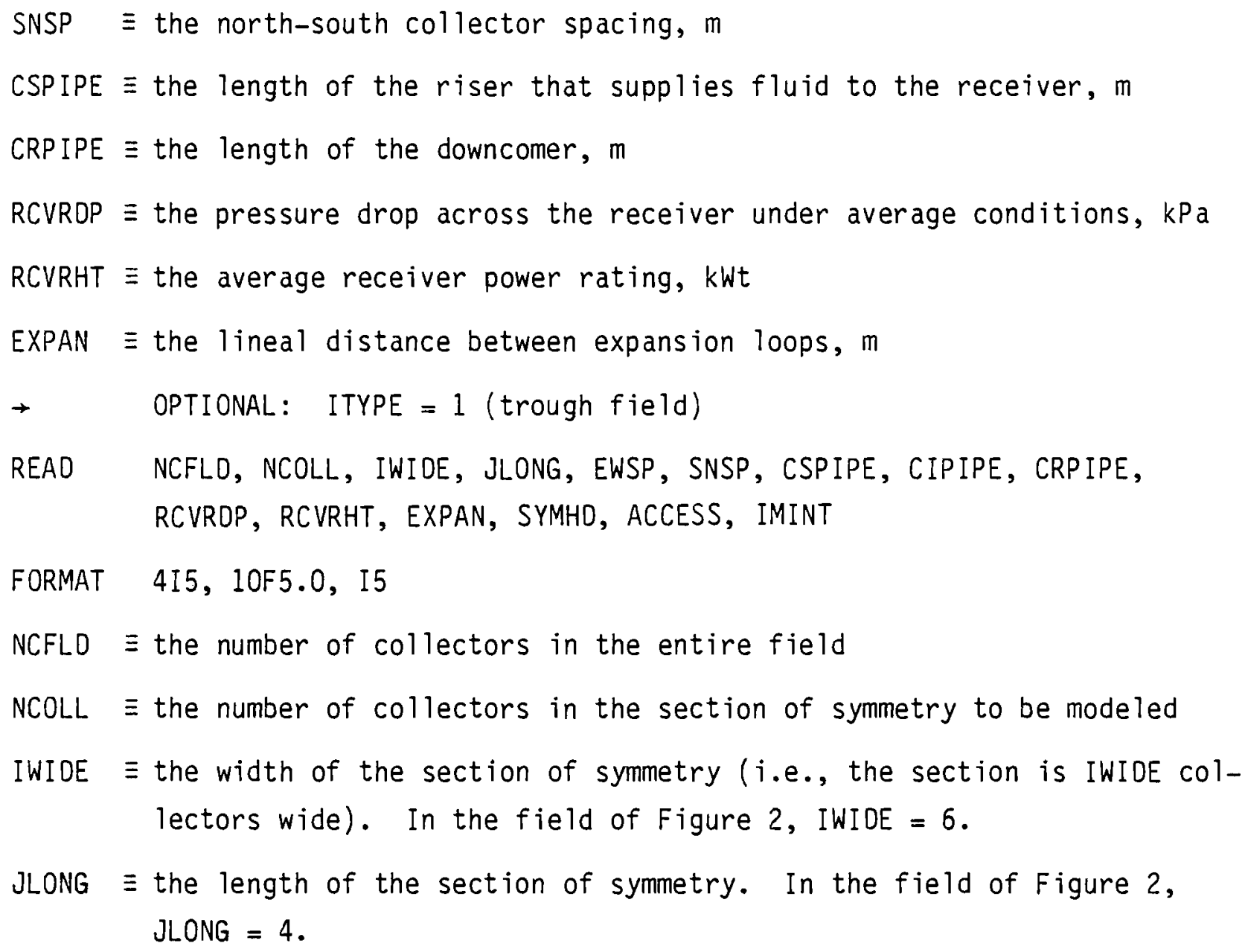


RCVRHT $\equiv$ the average receiver power rating, kWt

EXPAN $\equiv$ the lineal distance between expansion loops, $\mathrm{m}$

SYMHD $\equiv$ symmetry factor for the main headers. The headers are defined to be the pipes running from the central plant along the centerline of the field on an east-west axis. For fields in which the central plant is indeed at the center of the field, SYMHD $=2$. For fields in which the plant is at the east or west end, SYMHD $=1$.

ACCESS $\equiv$ the field access pipe length, $m$. The access pipe is the section running from the plant to the point where the first branches take off from it (section \#1 in Figure 2).

IMINT E the material index flag for the receiver connecting pipe. If IMINT $=1$, the supply side pipe and insulation tables are used in the design of this section. If IMINT $=2$, the return side tables are used. The user must predict the fluid pressure and temperature in the connecting pieces and select the appropriate materials accordingly.

$\rightarrow \quad$ OPTIONAL: ITYPE $=2$ (module field)

READ NCFLD, NCOLL, JLONG, RCVRHT, RCVRDP, EWSP, SNSP, EXPAN, SYMHD, ACCESS FORMAT 3I5, F10.0, 6F5.0

NCFLD $\equiv$ the number of modules in the entire field. A module consists of a previously optimized subfield of collectors; the modules are arranged in double rows along the headers.

NCOLL $\equiv$ the number of modules in the section of symmetry to be modeled JLONG $\equiv$ the length of the section of symmetry

RCVRHT $\equiv$ the net power output of the module under average conditions, kWt (the average receiver power multiplied by the number of receivers per module minus the rate of daytime heat loss)

RCVRDP $\equiv$ the overall module pressure drop, $\mathrm{kPa}$

EWSP $\equiv$ the east-west module spacing, $m$. Here again, the main headers are assumed to lie on an east-west axis. 
SNSP $\equiv$ the north-south module spacing, $m$

EXPAN $\equiv$ the lineal distance between expansion loops, $m$

SYMHD Esymmetry factor for the main headers, equal to the total number of identical main headers in the field divided by the number included in the simulation. Values of 1 or 2 are typical. However, if the modules are roughly square (EWSP=SNSP), the orientation of the headers is irrelevant and a value of SYMHO $=4$ might well lead to the lowest overall cost.

ACCESS $\equiv$ the field access pipe length, $m$.

In summary, the field specification group consists of a single card that provides the required information for the field type of interest. The fields are, of necessity, highly standardized; however, the experienced user will find that a wide variety of field shapes and sizes can be accommodated with little compromise. In laying out a field, the user must keep a number of factors in mind, including 1) the tradeoff between the cost of overly long pipe runs versus collector performance losses due to shading, 2) siting the plant judiciously with respect to the field to minimize the lengths of extremely largediameter sections, and 3) for trough fields, collectors should be placed in direct series to the extent that pressure drop limitations will allow.

A word of caution: early experience indicates that the module arrangement may be significantly more expensive than simple dish or trough fields of the same capacity. This option should be used sparingly and with sufficient checks to guarantee cost-effectiveness.

\section{GROUP 3: OPERATING CONOITIONS}

READ CFLOW, SPLYP, SPLYT, SPLYQ, TAMB, TNITE, CFP, CFH, ETAP, ETAM, PLOAD FORMAT F10.0, $10 F 5.0$

CFLOW $\equiv$ average flow rate per collector (or module), grams/sec

SPLYP $\equiv$ the pressure at which fluid is supplied to the main headers, $\mathrm{kPa}$ SPLYT $\equiv$ the fluid supply temperature, ${ }^{\circ} \mathrm{C}$ 
SPLYQ $\equiv$ the fluid supply quality (for a subcooled liquid, enter zero; for superheated vapor, enter 1)

TAMB $\equiv$ the average dayt ime ambient temperature, ${ }^{\circ} \mathrm{C}$

TNITE $\equiv$ the average nighttime ambient temperature, ${ }^{\circ} \mathrm{C}$

CFP $\equiv$ pumping capacity factor. This factor is equal to that portion of a 24-hour day during which the pump would operate if the flow rate versus time curve were levelized at the average value; numerically equivalent to the plant capacity factor.

CFH $\quad$ heating capacity factor. The working definition of this factor is the fraction of a 24-hour day during which the daytime heat loss model and the daytime ambient temperature are appropriate for determining the heat loss rate.

ETAP $\equiv$ pump efficiency under average conditions $(0<$ ETAP $<1.0)$

ETAM $\equiv$ motor efficiency under average conditions $(0<$ ETAM $<1.0)$

PLOAD $\equiv$ load pressure drop, $\mathrm{kPa}$. In many cases the field working fluid will pass through a heat exchanger or similar device at the central plant; PLOAD is simply the pressure drop across that device.

GROUP 4: WORKING FLUID PROPERTIES

READ NSAT, NPRES, NTEMP, CPNOM, TFRZ

FORMAT 3 I5, 2 F 10.0

NSAT $\equiv$ the number of sets of data in the saturated liquid table $(0 \leq N S A T \leq 5)$

NPRES $\equiv$ the number of pressures for which superheated vapor tables are to be read $(0 \leq$ NPRES $\leq 5)$

NTEMP $\equiv$ the number of sets of data in each superheated vapor table $(0 \leq$ NTEMP $\leq 5)$

CPNOM $\equiv$ the average specific heat for the fluid in the saturated liquid state over the range of anticipated operating pressures, $\mathrm{J} / \mathrm{g} \cdot{ }^{\circ} \mathrm{C}$ 
TFRZ $\equiv$ the freezing temperature of the working fluid, ${ }^{\circ} \mathrm{C}$

$\rightarrow \quad$ OPTIONAL: NSAT $\geq 2$

READ (PP(I), TT(I), $\operatorname{VVF}(I), \operatorname{VVG}(I), \operatorname{HHF}(I), \operatorname{HHG}(I), \operatorname{UUF}(I), I=1, N S A T)$

FORMAT $7 F 10.0$

PP $\quad \equiv$ the pressure to which the accompanying saturation properties correspond, $\mathrm{kPa}$

$T \quad \equiv$ the saturation temperature, ${ }^{\circ} \mathrm{C}$

VVF $\equiv$ the saturated liquid specific volume, $\mathrm{cm}^{3} / \mathrm{g}$

VVG $\equiv$ the saturated vapor specific volume, $\mathrm{cm}^{3} / \mathrm{g}$

HHF $\equiv$ the saturated liquid enthalpy, $\mathrm{J} / \mathrm{g}$

HHG $\equiv$ the saturated vapor enthalpy, J/g

UUF $\equiv$ the saturated liquid viscosity, $\mathrm{g} / \mathrm{cm}-\mathrm{sec}$

$\rightarrow \quad$ OPTIONAL: NPRES $\geq 2$ (if NPRES $\geq 2$, NTEMP must also be)

READ (PSUP(I), (TSUP(I, J), $\operatorname{HSUP}(I, J), \operatorname{VSUP}(I, J), \operatorname{USUP}(I, J), J=1$, NTEMP), I $=1$, NPRES)

FORMAT $5 F 10.0$

PSUP $\equiv$ the pressure to which the accompanying superheat properties correspond, $\mathrm{KPa}$

TSUP $\equiv$ the superheat temperature, ${ }^{\circ} \mathrm{C}$

HSUP $\equiv$ the enthalpy, $\mathrm{J} / \mathrm{g}$

VSUP $\equiv$ the specific volume, $\mathrm{cm}^{3} / \mathrm{g}$

USUP $\equiv$ the viscosity, $\mathrm{g} / \mathrm{cm}-\mathrm{sec}$

The ETRANS fluid property tables are set up much like tables one finds in textbooks. Each card of the saturation table includes one pressure and the associated saturation properties. Superheat tables are read in for up to five pressures. Each card within a table includes the pressure, temperature, enthalpy, specific volume, and viscosity. The property subroutine (PROP) works 
by performing linear interpolations on the supplied tabular data; thus, at least two sets must be supplied per table. PROP does not extrapolate; the user must therefore be certain to bound the full range of conditions to be encountered. Either table (saturation or superheat) may be left out if inappropriate, such as a saturation table for an air system. A look at Figure A.1 should dispel any confusion that might exist concerning the input format.

GROUP 5: FINANCIAL INFORMATION

READ IKNOW, GI, G(1), G(2), N, PCT, YCO, YB, PWRCST, HTCST, TRCCST

FORMAT I5, 10F5.0

IKNOW $\equiv$ computation flag. IKNOW $=0$, read the basic parameters necessary to compute $K, C R F$, and FCR (see below); IKNOW = 1, reak $K, C R F$ and FCR directly

GI $\equiv$ general annual inflation rate during plant construction $(0 \leq \mathrm{GI}<1.0)$

$G(1) \equiv$ inflation rate on capital items purchased during plant construction

$G(2) \quad \equiv$ inflation rate on operations and maintenance costs

N $\quad \equiv$ plant life, years

PCT $\equiv$ plant construction time, years

$Y C O \equiv$ first year of commercial operation

YB $\equiv$ base year for prices

PWRCST = purchase price for pump energy, $\$ / \mathrm{kWh}$

HTCST $\equiv$ replacement cost of heat loss, $\$ / \mathrm{kWh}$

TRCCST $\equiv$ purchase price for heat trace energy, $\$ / \mathrm{kWh}$

$\rightarrow \quad$ OPTIONAL: $\quad$ IKNOW $=0$

READ TAXR, BETA1, BETA2, KD, KC, KP, DFRAC, CFRAC, PFRAC

FORMAT $9 F 5.0$

TAXR $\equiv$ effective income tax rate $(0 \leq \operatorname{TAXR}<1.0)$ 


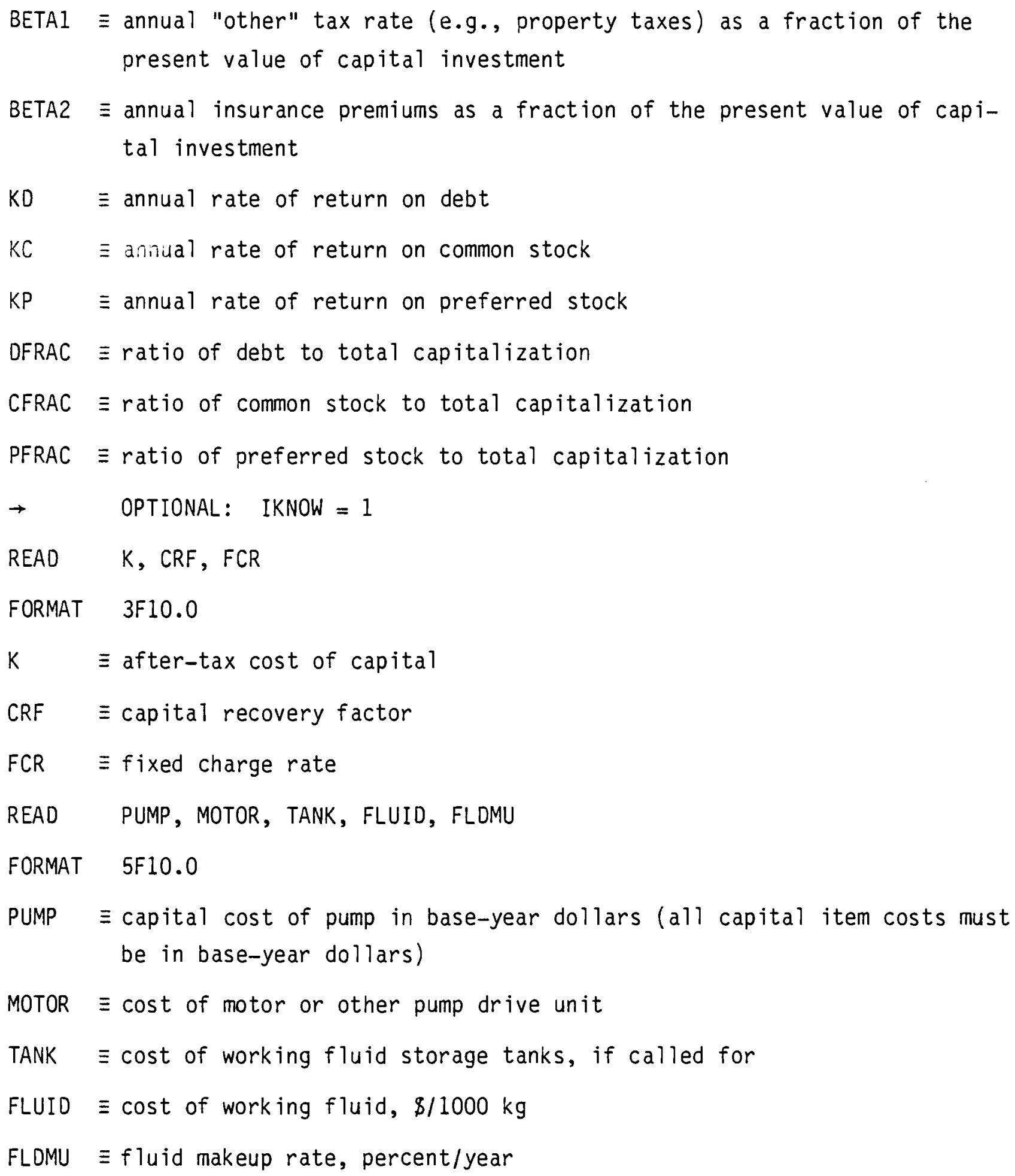

The user has the option of reading in the owner-dependent financial data which are used directly in the code (K, CRF, and FCR) or the more fundamental parameters upon which they are based. In the latter case, ETRANS calculates 
K, CRF, and FCR according to the formulas presented in Doane et al. (1976). Users unfamiliar with the terminology of this group should consult Doane et al.

The costs of the pump, motor, and tank are included to provide a complete accounting of the transport system capital items. Other items that do not directly impact the cost of the individual pipe sections (support building, spare parts inventory) can be included with any of these three variables.

GROUP 6: PIPING AND INSULATION DATA

This group is generally the largest of the six and certainly the most complicated to set up. The user may supply one set of piping specifications to be used on both sides of the field or separate sets for the supply and return sides (in that order). The same is true for the insulation data. Nested DO loops are used to read both the piping and insulation tables. These will be indicated in this guide for maximum clarity. Close examination of Figure A.1 will prove quite enlightening, as well.

READ NMAT, NINS

FORMAT 2 I5

NMAT $\equiv$ the number of piping tables to be read in $(1 \leq$ NMAT $\leq 2)$

NINS $\equiv$ the number of insulation tables to be read in $(1 \leq$ NINS $\leq 2)$

$\star \star \star \star \quad$ DO 210 IM $=1$, NMAT

READ NDIA(IM), EXCO(IM), PIPERO(IM), PIPECP(IM)

FORMAT I10, 3F10.0

NDIA $\equiv$ number of pipe sizes contained in the table

EXCO $\equiv$ the thermal expansion coefficient of the pipe material, $\mathrm{K}^{-1}$

PIPERO $\equiv$ pipe material density, $\mathrm{g} / \mathrm{cm}^{3}$

PIPECP $\equiv$ pipe material specific heat, $\mathrm{J} / \mathrm{g} \cdot{ }^{\circ} \mathrm{C}$

** DO $200 \mathrm{I}=1$, NDIA(IM)

READ DIA(I, IM), WALL(I, IM), SCH(I, IM), PIPEC(I, IM), SHOPWC (I, IM), FLOWC (I, IM), GATEC(I, IM), CONTRC(I, IM) 


\section{FORMAT $8 F 10.0$}

OIA $\equiv$ pipe inside diameter, $\mathrm{cm}$

WALL $\equiv$ pipe wall thickness, cm

$\mathrm{SCH} \equiv$ pipe schedule

PIPEC $\equiv$ cost of pipe delivered to the site, $\$ / \mathrm{m}$

SHOPWC $\equiv$ cost per shop weld

FLDWC $\equiv$ field weld cost

GATEC $\equiv$ installed cost of a flanged gate valve

CONTRC $\equiv$ installed cost of a flanged control valve, including control wiring, thermocouple installation, and drive hookup (electrical, hydraulic, or pneumatic)

READ CROSSC(I, IM), TEEC(I, IM), ELLC (I, IM), ELL45C(I, IM), FLNGEC(I, IM), REDCRC(I, IM), DIFFUC(I, IM)

FORMAT $7 F 10.0$

CROSSC $\equiv$ cost of a pipe cross delivered to the site but not yet installed (typical of all fittings)

TEEC $\equiv$ tee cost

ELLC $\equiv$ long-radius ell cost

ELL45C $\equiv$ long-radius $45^{\circ}$ ell cost

FLNGEC $\equiv$ slip-on flange cost

REDCRC $\equiv$ cost of the reducer that reduces down to size DIA(I, IM) from the next larger size

DIFFUC $\equiv$ cost of the diffuser that expands up to size DIA(I, IM) from the next smaller size

READ SPRT(I, IM), BVL(I, IM), SPRTC(I, IM), BENDC(I, IM), HNDLC(I, IM), TRACEC(I, IM), PMULT(I, IM), INDX (I, IM)

FORMAT 7F10.0, I10 


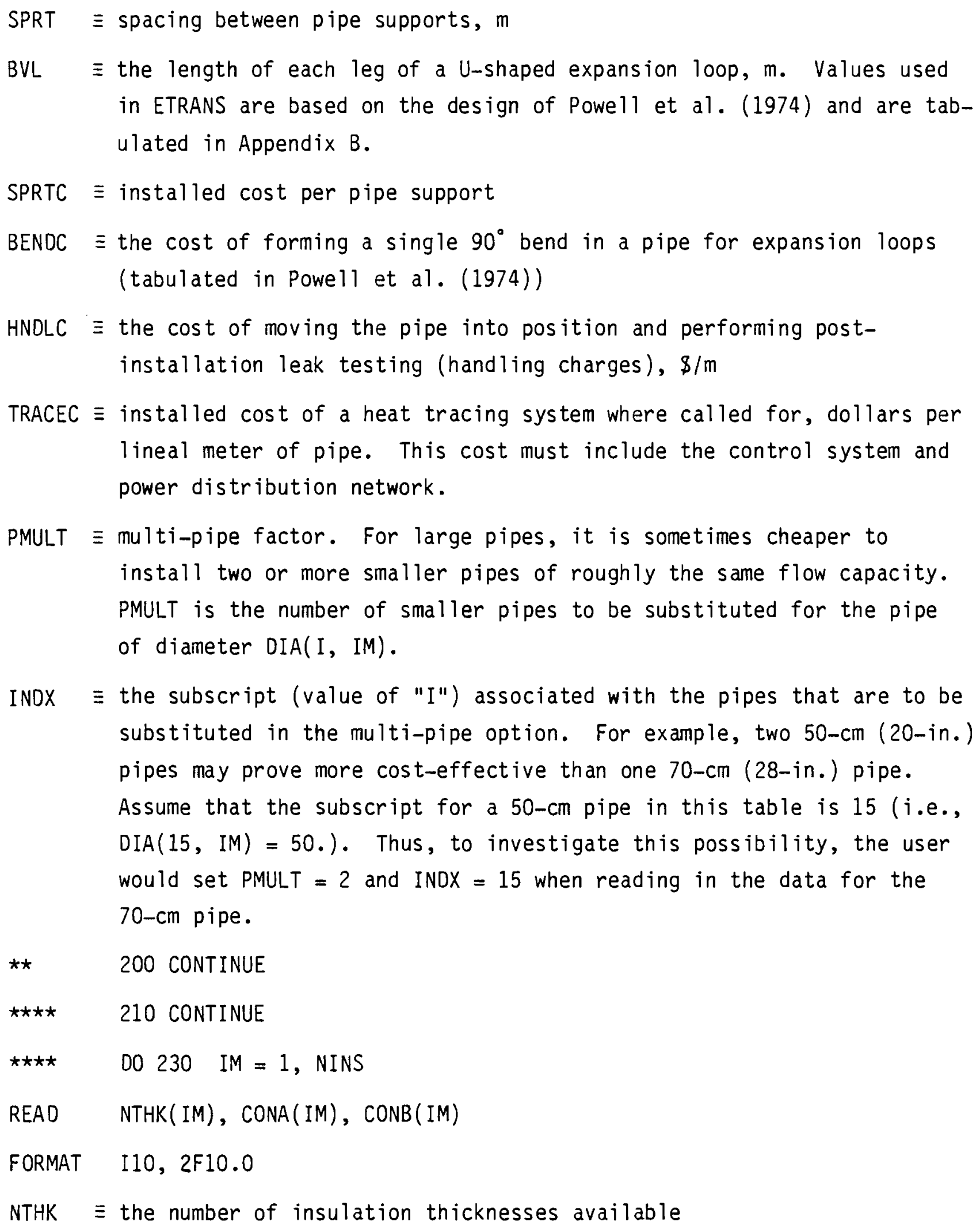
substituted in the multi-pipe option. For example, two 50-cm (20-in.) pipes may prove more cost-effective than one 70-cm (28-in.) pipe. Assume that the subscript for a $50-\mathrm{cm}$ pipe in this table is 15 (i.e., $\operatorname{DIA}(15, I M)=50$.$) . Thus, to investigate this possibility, the user$ would set PMULT $=2$ and INDX $=15$ when reading in the data for the 70-cm pipe.

** 200 CONTINUE

$\star \star \star \star \quad 210$ CONTINUE

$\star \star \star \star \quad$ DO 230 IM $=1$, NINS

READ NTHK(IM), CONA (IM), CONB (IM)

FORMAT I10, 2F10.0

NTHK $\equiv$ the number of insulation thicknesses available 
CONA, $\equiv$ constants in a linear expression relating insulation thermal conducCONB tivity $\left(k, W / m-{ }^{\circ} C\right)$ to the mean fluid-air temperature ( $T$, degrees $C$ ): $k=\operatorname{CONA}(T)+\operatorname{CONB}$

READ (THK(I, IM), I $=1$, NTHK(IM))

FORMAT $8 F 10.0$

THK $\equiv$ insulation thickness, $\mathrm{cm}$

$\star \star \quad$ DO $220 \quad \mathrm{I}=1$, NDIA(IM)

READ (INSLC(I, J, IM), J = $1, \operatorname{NTHK(IM))~}$

FORMAT $8 F 10.0$

INSLC $\equiv$ installed cost of insulation, dollars per lineal meter of pipe ** 220 CONTINUE

$\star \star \star \star \quad 230$ CONTINUE.

One final note: ETRANS is not a mature code, and the input will undoubtedly change as the code evolves. Careful study of subroutine SETIN will hopefully clear up any problems that arise due to use of an outdated input guide.

\section{REFERENCES}

Doane, J. W., et al. 1976. The Cost of Energy from Utility-Owned Solar Electric Systems. ERDA/JPL-1012-7613, Jet Propulsion Laboratory, Pasadena, California.

Powe11, J. C., et al. 1974. Dynamic Conversion of Solar-Generated Heat to Electricity. NASA CR-134724, Honeywell, Inc., Minneapolis, Minnesota, and Black \& Veatch, Kansas City, Missouri. 


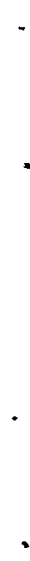


APPENDIX B

EXPANSION LOOP SPECIFICATIONS 


\section{EXPANSION LOOP SPECIFICATIONS}

This appendix briefly details the shape and size of expansion loops used in ETRANS. The loops are based on the design of Powell et al. (1974) and consist simply of U-shaped projections located at user-specified intervals in each run of pipe. The height of the loop is a function of pipe diameter, as indicated in Table B.1. The tabulated values correspond to a system constructed of carbon steel pipe operating at a nominal temperature of $288^{\circ} \mathrm{C}$ with expansion loops located every $24.4 \mathrm{~m}$.

Common sense indicates that expansion loop height should be a function of not only pipe diameter but other factors as well: 1) operating temperature, 2) inter loop spacing, and 3) the pipe material thermal expansion coefficient. ETRANS accounts for these factors in a simple way by making loop height directly proportional to each; the design of Powell et al. (1974) is used as the base case. 
TABLE B.1. Expansion Loop Height Specification for Various Pipe Diameters

\begin{tabular}{|c|c|c|c|}
\hline \multicolumn{2}{|c|}{ Pipe Diameter } & \multicolumn{2}{|c|}{ Loop Height } \\
\hline$(\mathrm{cm})$ & (in.) & $(m)$ & $(\mathrm{ft})$ \\
\hline 1.27 & 0.5 & 2.44 & 8 \\
\hline 2.54 & 1 & 2.74 & 9 \\
\hline 3.81 & 1.5 & 3.35 & 11 \\
\hline 5.08 & 2 & 3.66 & 12 \\
\hline 6.35 & 2.5 & 4.12 & 13.5 \\
\hline 7.62 & 3 & 4.57 & 15 \\
\hline 8.89 & 3.5 & 4.88 & 16 \\
\hline 10.2 & 4 & 5.18 & 17 \\
\hline 12.7 & 5 & 5.64 & 18.5 \\
\hline 15.2 & 6 & 6.25 & 20.5 \\
\hline 20.3 & 8 & 7.01 & 23 \\
\hline 25.4 & 10 & 7.62 & 25 \\
\hline 30.5 & 12 & 8.54 & 28 \\
\hline 35.6 & 14 & 8.99 & 29.5 \\
\hline 40.6 & 16 & 9.60 & 31.5 \\
\hline 45.7 & 18 & 10.2 & 33.5 \\
\hline
\end{tabular}

Source: J. C. Powell et al. 1974. Dynamic Conversion of Solar Generated Heat to Electricity. NASA CR-134724, Honeywell, Inc., Minneapolis, Minnesota, and Black \& Veatch, Kansas City, Missouri. 


\section{DISTRIBUTION}

No. of

Copies

\section{OFFSITE}

A. A. Churm

DOE Patent Division

9800 S. Cass Avenue

Argonne, IL 60439

G. W. Braun

Division of Solar Thermal Energy Systems

U.S. Department of Energy

600 E Street, NW

Washington, DC 20585

L. Melamed

Division of Solar Thermal Energy Systems

U.S. Department of Energy

600 E Street, NW

Washington, DC 20585

6 J. E. Rannels

Division of Solar Thermal Energy Systems

U.S. Department of Energy

600 E Street, NW

Washington, DC 20585

27 DOE Technical Information Center

J. R. Biddle Jet Propulsion Laboratory

California Institute of Technology 4800 Oak Grove Drive

Pasadena, CA 91103

J. M. Bowyer

Jet Propulsion Laboratory

California Institute of Technology 4800 Oak Grove Drive

Pasadena, CA 91103
No. of

Copies

\section{T. Fujita}

Jet Propulsion Laboratory

California Institute of Technology 4800 Oak Grove Drive

Pasadena, CA 91103

B. C. Gajanana

Jet Propulsion Laboratory

California Institute of Technology 4800 Oak Grove Drive

Pasadena, CA 91103

E. J. Hanseth

Jet Propulsion Laboratory

California Institute of Technology 4800 Oak Grove Drive

Pasadena, CA 91103

W. R. Revere

Jet Propulsion Laboratory

California Institute of Technology 4800 Oak Grove Drive

Pasadena, CA 91103

K. Subramanian

Room E. 1131

P. 0. Box 2053

Ford Motor Company

Dearborn, MI 48121

P. E. Liley

School of Mechanical Engineering

Purdue University

West Lafayette, IN 47907

R. D. Smith

Rocket Research Company

York Center

Redmond, WA 98052 
No. of

Copies

v. Dugan

Sandia Laboratories

P.0. Box 5800

Albuquerque, NM 87185

M. J. Fish

Energy Systems Studies Division Sandia Laboratories

Livermore, CA 94550

J. J. I annucci

Energy Systems Studies Division

Sandia Laboratories

Livermore, CA 94550

A. Herlevich

Solar Energy Research Institute

1536 Cole Boulevard

Golden, CO 80401

D. W. Hooker

Solar Energy Research Institute 1536 Cole Boulevard

Golden, CO 80401

D. Percival

Solar Energy Research Institute 1536 Cole Boulevard

Golden, CO 80401
No. of

Copies

ONSITE

2 DOE Richland Operations Office

H. E. Ransom

R. K. Stewart

74 Pacific Northwest Laboratory

W. J. Apley (3)

J. S. Barnhart (57)

S. P. Bird

D. R. Brown

A. J. Currie

M. K. Drost

J. A. Fort

W. W. Laity (2)

Technical Information (5)

Publishing Coordination (SH)(2) 